\title{
Houndstooth Upcycle
}

\author{
Jung Eun Lee, Virginia Tech, USA
}

Keywords: sustainability, upcycle, houndstooth, handwoven

\section{Contextual Review and Concept}

Textile manufacturing and clothing production processes cause significant harm to the environment via land, air, and water pollutions (Fibre2Fashion, 2012). In particular, cotton, the principal material for t-shirts, has been called "the world's dirtiest crop" because it is the crop with the highest amounts of harmful pesticides and fertilizers, and has the most dangerous pesticides sprayed on it (Gam, Cao, Farr, \& Heine, 2009; Fibre2Fashion, 2012; Klein, 2018). The second most commonly used pesticide for the cotton crop (i.e., Aldicarb) is extremely harmful to human health; as little as one drop can kill a human upon absorption into the skin (Klein, 2018). Apparel manufacturing processes that convert cotton into clothing are also intensive chemical procedures that involve dyeing, finishing, and other operations, using numerous toxic chemicals like harsh softeners, brighteners, and heavy metals (Klein, 2018; Gam et al., 2009). However, most people do not think that the clothes they purchase will result in significant environmental problems (Fibre2Fashion, 2012). The average American throws away about 80 pounds of used garments annually, and, in the United States, used textile waste exceeds 15 million tons every year (Leblanc, 2019). Therefore, consumers must recognize the severity of environmental problems caused by thoughtless clothing purchases and understand how to reuse clothing and textiles to avoid pollution and energy wasting.

The purpose of this design work is to create sustainable garments and achieve a high-quality look by upcycling used t-shirts. Upcycling is recycling and reusing discarded materials to recover the item's intrinsic value and generate higher value and quality products, which provides economic and environmental benefits (Han, Chan, Venkatraman, Apeagyei, Cassidy, \& Tyler, 2017). With this project, I explore how to take worn t-shirts with stains and holes, which have diminished in value as garments, and use the materials to create entirely new and valuable pieces. This two-piece set design was inspired by the Chanel tweed suit, initially introduced by French designer Gabrielle Coco Chanel in the 1920s. Chanel designed the tweed suit to free women's bodies from the restricting corset (Vernose, 2020). The suit represents sophistication and elegance, and symbolizes Chanel; women around the world admire Chanel and her creations (Vernose, 2020). Channeling Chanel's spirit, this current design illustrates how clothing with little life left can transform into valuable pieces, like a Chanel tweed suit. 
While previous designers have created garments by upcycling t-shirts, they were limited in their use of knitting techniques or plain weaves to create those garments (Lee, 2017; Salusso \& Ji, 2018). Moreover, their final garments presented dresses with a nostalgic (Salusso \& Ji, 2018) and bohemian look (Lee, 2017), which still feature casual looks from t-shirts. Thus, this design challenges whether upcycled garments can completely transform to achieve an even more expensive look than when they were t-shirt. It is also a challenge to fabricate the twill weave to create a jacket, which has not been created by any previous designers.

\section{Aesthetic Properties and Visual Impact}

I create unique textile woven surface designs and upcycled garments by integrating sustainable materials and the craft of hand weaving. To achieve this design and drastically increase the value of clothing by upcycling garments, aesthetic properties and visual impact were critical in considering color, shape, balance, and contrast. The houndstooth check stands out the best by using the biggest color contrast between two yarns, so I used navy and white to create a houndstooth pattern for the jacket. I added a braided trim using red, navy, and white around the center front and neckline on the jacket as an accent, which leads observers to focus on the wearer's face. The skirt is woven using navy, red, and white to create a vibrant look and achieve color contrast between navy and red. Because I wanted to create a luxurious look, I tried to keep the garments simple and created symmetry and balance. At the same time, the color contrast adds an interesting design element and a visual impact on the overall design.

\section{Process, Technique, and Execution}

This design is constructed using my husband's old t-shirts with holes and stains. To create tshirt yarns, I cut about ten t-shirts into $1 / 2$-inch strips. Then, using the characteristic of jersey fabric in which the cut edges curl, I stretched each strip to make t-shirt yarns. To create the houndstooth check, four navy and four white yarns were used interchangeably for warp and weft yarns, and they were handwoven in a $2 \times 2$ twill weave. Additionally, to create the skirt fabric, I used Adobe Photoshop to design plaid patterns and project how the plaid would look. Then, I developed three colors (red, navy, and white) of t-shirt yarns. I used two yarns for each color repeatedly for warp and weft yarns, which were woven in a plain weave. Pattern making by draping was used to create patterns for the jacket and skirt. I laid and marked handwoven fabrics with the developed patterns and applied zigzag stitches around the pattern lines to hold all of the t-shirts yarns together before cutting the fabrics. After cutting and constructing the handwoven fabrics for the jacket and skirt, I added braided trim using red, navy, and white t-shirt yarns around the center front and neckline on the jacket.

Page 2 of $\mathbf{5}$

(c) 2020 The author(s). Published under a Creative Commons Attribution License (https://creativecommons.org/licenses/by/4.0/), which permits unrestricted use, distribution, and reproduction in any medium, provided the original work is properly cited.

IT AA Proceedings, \#77 - https:// itaaonline.org 


\section{Cohesion, Design Contribution, and Innovation}

The dress provides cohesiveness in the overall garment design for a sustainable two-piece suit and conveys a luxurious look by upcycling t-shirts and incorporating a houndstooth pattern. Further, this design is unique and original, as I integrated the upcycling of used textiles and handwoven techniques of houndstooth check. Unlike upcycled t-shirt garments previously created by designers, which offered casual looks, the resulting garments look beautiful, modern, and sophisticated. I want to show that sustainable materials can transform into fancy and valuable garments. This garment also used hand twill weave, resulting in a houndstooth pattern on a jacket, with which previous designers have not experimented.

This design project combined used upcycling sustainable design practice and handwoven techniques to give a new life to used t-shirts. Over-consumption and over-production to meet consumers' need to find new fashion products have resulted in environmental issues of waste, pollution, and the exploitation of natural sources. This project was developed to inspire consumers to reconsider the used garments they often throw away without consideration for reusing, reforming, and upcycling the materials. This design project can inspire designers to look at post-consumer textiles as opportunities to upcycle by utilizing the tons of textile waste produced to satisfy the constant demand for new fashion.

\section{References}

Fibre2Fashion (2012). Various pollutants released into environment by textile industry. Retrieved from https:/www.fibre2fashion.com/industry-article/6262/various-pollutantsreleased-into-environment-by-textile-industry

Gam, H.J., Cao, H., Farr, C., \& Heine, L. (2009). C2CAD: A sustainable apparel design and production model. International Journal of Clothing Science and Technology, 21(4) 166-179.

Han, S. L., Chan, P. Y., Venkatraman, P., Apeagyei, P., Cassidy, T., \& Tyler, D. J. (2017). Standard vs. upcycled fashion design and production. Fashion Practice, 9(1), 69-94.

Klein, L.L. (2018). Cotton: The world's "dirtiest" crop. Retrieved from https://www.organicauthority.com/buzz-news/cotton-the-worlds-dirtiest-crop

Leblanc, R. (2019). Textile and garment recycling facts and figures. Retrieved from https://www.thebalancesmb.com/textile-recycling-facts-and-figures-2878122

Lee, J.E. (2017). T-shirt resurgence. International Textile and Apparel Association (ITAA) Annual Conference Proceedings. https://lib.dr.iastate.edu/cgi/viewcontent.cgi?article=2156\&context=itaa_proceedings

Salusso, C., \& Ji, Y. (2018). Upcycling approach to designing to highlight traditional weaving and knitting techniques. International Textile and Apparel Association (ITAA) Annual

Page 3 of $\mathbf{5}$

(c) 2020 The author(s). Published under a Creative Commons Attribution License (https://creativecommons.org/licenses/by/4.0/), which permits unrestricted use, distribution, and reproduction in any medium, provided the original work is properly cited.

IT AA Proceedings, \#77 - https:// itaaonline.org 


\section{Conference Proceedings.}

https://lib.dr.iastate.edu/cgi/viewcontent.cgi?article=3238\&context=itaa_proceedings

Vernose, V. (2020). The history of the Chanel tweed suit. Retrieved from

https://www.crfashionbook.com/fashion/a26551426/history-of-chanel-tweed-suit/ 

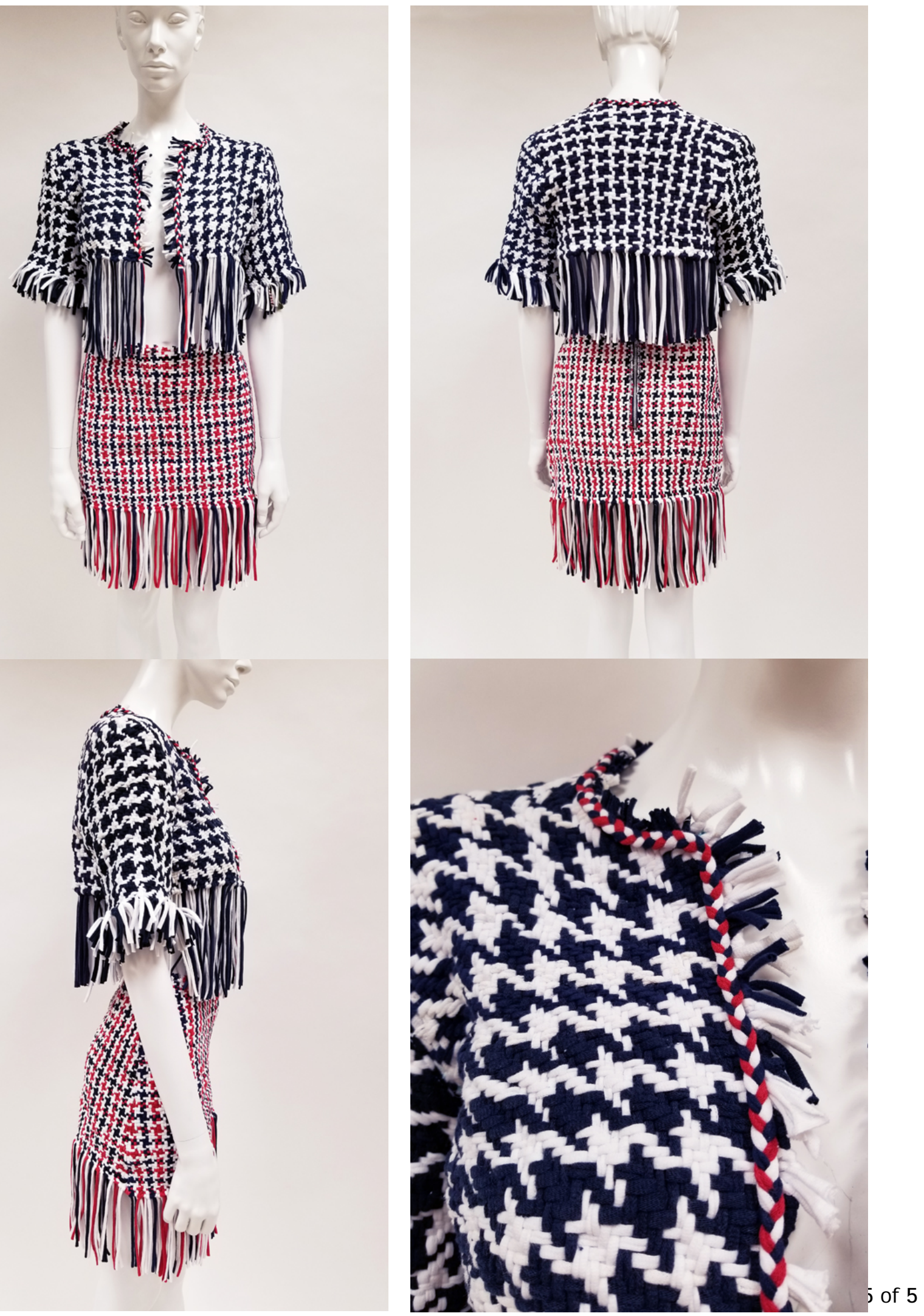

(c) 2020 The author(s). Published under a Creative Commons Attribution License

(https://creativecommons.org/licenses/by/4.0/), which permits unrestricted use, distribution, and reproduction in any medium, provided the original work is properly cited.

IT AA Proceedings, \#77 - https:// itaaonline.org 